\title{
Spontaneous Resolution of Post-Traumatic Direct Carotid-Cavernous Fistula
}

\author{
Varun Naragum ${ }^{a}$ b $\quad$ Glenn Barest ${ }^{b} \quad$ Mohamad AbdalKader ${ }^{b}$ \\ Katharine M. Cronk ${ }^{c}$ Thanh N. Nguyen ${ }^{a-c}$ \\ Departments of a Neurology, ${ }^{b}$ Radiology, and ${ }^{\mathrm{C}}$ Neurosurgery, Boston Medical Center, \\ Boston, MA, USA
}

Keywords
Carotid-cavernous fistula $\cdot$ Barrow classification $\cdot$ Spontaneous resolution

\begin{abstract}
Post-traumatic carotid-cavernous fistulas are due to a tear in the wall of the cavernous carotid artery, leading to shunting of blood into the cavernous sinus. These are generally highflow fistula and rarely resolve spontaneously. Most cases require endovascular embolization. We report a case of Barrow type A carotid-cavernous fistula which resolved spontaneously.
\end{abstract}

(c) 2017 S. Karger AG, Basel

\section{Introduction}

Direct carotid-cavernous fistula (CCF) is an abnormal communication between the carotid artery cavernous segment and the cavernous sinus. Unlike brain cerebral arteriovenous malfomations, they are acquired lesions. Because of direct shunting of arterial blood into the cavernous sinus and subsequently into the superior ophthalmic vein, they often present with pulsatile exophthalmos, diplopia, raised intraocular pressure, and intracranial hemorrhage if shunting occurs retrograde into the adjacent cerebral veins [1-3]. In the Barrow classification [4], direct or type A fistulas are due to a breach in the wall of the cavernous carotid artery leading to shunting of blood into the cavernous sinus. The most common etiology of direct CCF is related to trauma or less commonly rupture of a cavernous aneurysm. Owing to their high-flow nature and aggressive clinical course, direct CCF rarely 

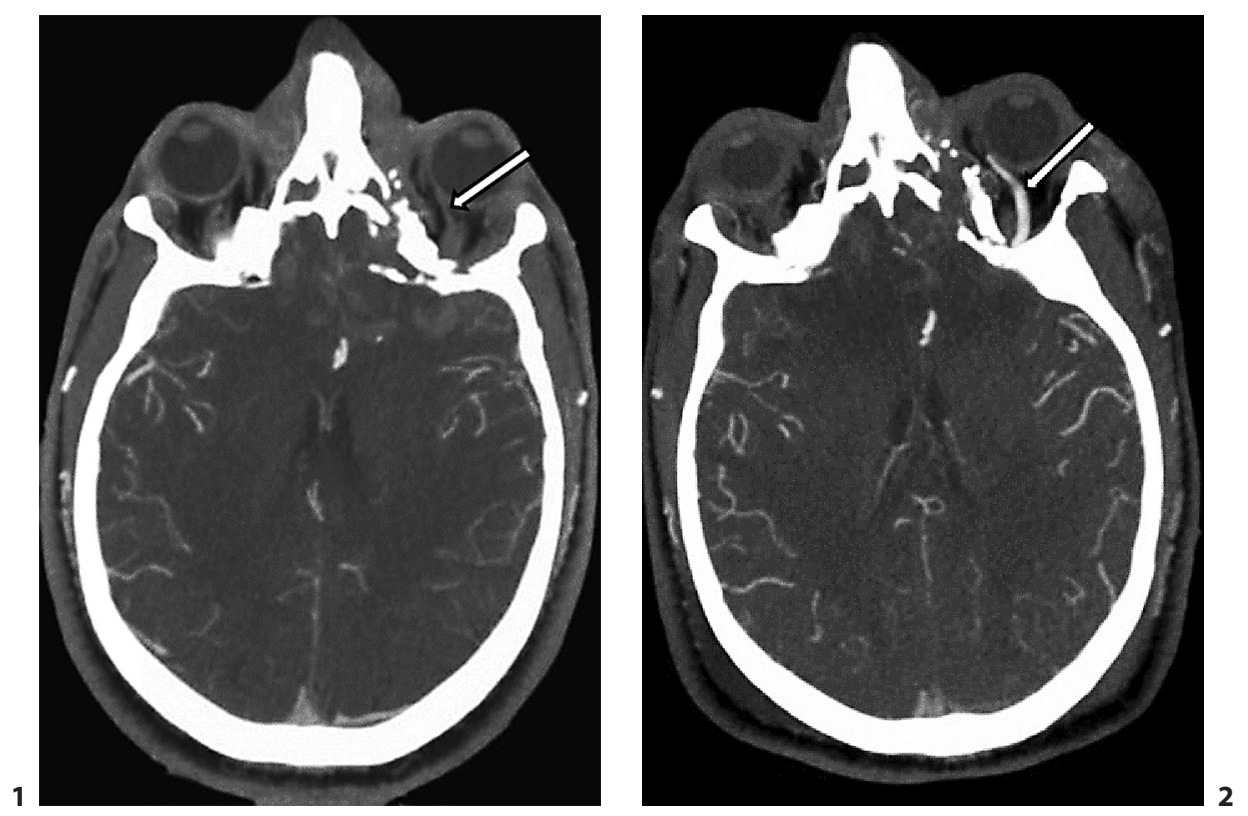

Fig. 1. Maximum-intensity pixel projection from initial contrast-enhanced CT angiogram of the head shows a normal-caliber left superior ophthalmic vein.

Fig. 2. Maximum-intensity pixel projection from contrast-enhanced CT angiogram of the head shows a dilated left superior ophthalmic vein compared to exam from 1 week earlier.

resolve spontaneously and often require endovascular embolization to prevent potential vision loss [5]. We report a case of spontaneous resolution of a direct CCF several days after diagnostic catheter angiography.

\section{Case Report}

A 54-year-old man involved in a motor vehicle rollover was admitted unresponsive with a Glasgow Coma Scale score (GCS) of 8 (eye response $=1$, verbal response $=2$, motor response $=5$ ). He had a midline frontal scalp laceration, frontal bone fractures, left orbital edema and epistaxis. CT scan of the head showed subarachnoid hemorrhage, intraventricular hemorrhage, subdural hemorrhage, and a midline shift of $7 \mathrm{~mm}$ without evidence of herniation. Initial CT angiogram did not reveal any vascular abnormalities (Fig. 1). An intraparenchymal bolt was placed for clinical suspicion of raised intracranial pressure (ICP). ICP was found to be greater than $20 \mathrm{~cm} \mathrm{H}_{2} \mathrm{O}$. He continued to have depressed mental status (GCS between 8 and 11). Bilateral periorbital edema was present and both conjunctivae were injected. Pupils were $2.5 \mathrm{~mm}$ and fixed. Oculocephalic reflexes were not performed because the patient was in a cervical collar. CT angiogram was repeated on day 7 because of sustained high ICP. It revealed a dilated left superior ophthalmic vein (Fig. 2), which was not seen on the initial CT angiogram. Catheter angiography revealed a direct left CCF with drainage to the left superior ophthalmic vein (Fig. 3). No other arterial feeders were noted. Attempts to cannulate the fistula via transarterial approach were unsuccessful. The decision was made to bring the patient back for repeat angiography for possible transarterial or transvenous embolization of the fistula.

Because of his continued poor mental status, an MRI was performed on day 15 (Fig. 4). It did not demonstrate asymmetry of the superior ophthalmic vein flow voids. The patient underwent repeat catheter angiogram 14 days after the initial study, which revealed complete resolution of the CCF (Fig. 5).

Over the coming days, his neurological status continued to improve and ICP normalized. He was successfully extubated. Mental status improved progressively and no speech deficits were identified. He could follow commands but continued to have difficulty with executive functioning. He was subsequently transferred to rehab. At 3 months follow-up in clinic, he was noted to have made significant recovery and was independent 


\section{Interventional Neurology}

Fig. 3. Left internal carotid angiogram (early arterial phase) demonstrates a direct carotid-cavernous fistula and early (retrograde) drainage to the dilated left superior ophthalmic vein.

Fig. 4. MRI (FLAIR) image obtained 14 days later shows symmetric normal caliber flow voids of the superior ophthalmic veins (and a small subdural hematoma).

Fig. 5. Repeat left internal carotid angiogram (early arterial phase) confirmed spontaneous resolution of the carotid-cavernous fistula.

\begin{tabular}{l|l}
\hline Intervent Neurol 2018;7:1-5 \\
\hline DOI: 10.1159/000480303 & $\begin{array}{l}\text { @ 2017 S. Karger AG, Basel } \\
\text { www.karger.com/ine }\end{array}$ \\
\hline
\end{tabular}

Naragum et al.: Spontaneous Resolution of Post-Traumatic Direct Carotid-Cavernous Fistula
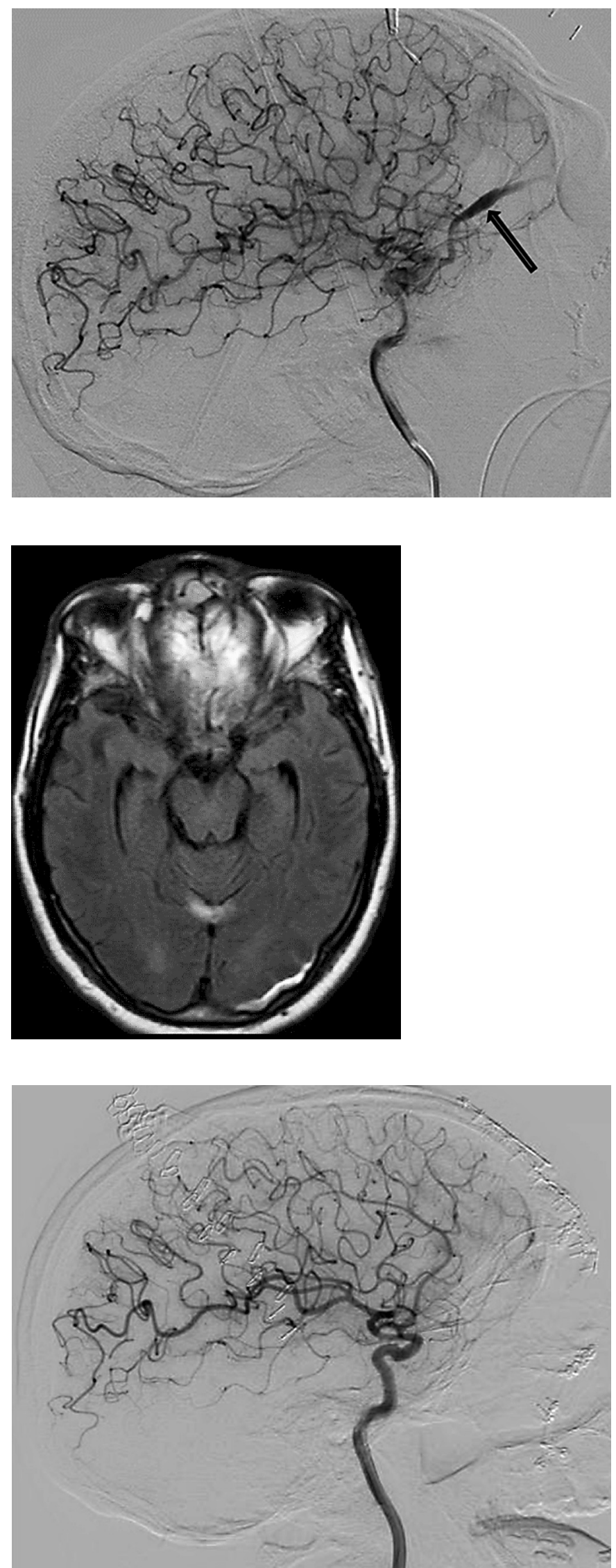
with activities of daily living. He had residual cognitive difficulties with executive functions due to frontal contusions. Eye exam was significant for diplopia on horizontal gaze due to left abducens palsy. Neuroophthalmological evaluation revealed decreased vision in the left eye due to traumatic optic neuropathy. No conjunctival erythema or pulsatile exophthalmos was seen. No further vascular imaging was done.

\section{Discussion}

Based on anatomical-angiographic characteristics, CCF were classified by Barrow et al. [4] into types A, B, C, and D. Type A fistulas result from direct communication between the intracavernous carotid artery and the cavernous sinus. The common causes include ruptured aneurysm or traumatic rupture. Type B, C, and D fistulas are indirectly fed by dural feeders from the internal carotid artery, external carotid artery, or both, respectively. These are generally considered low-flow fistulas.

Type A fistulas, because of the direct communication, are usually of a high-flow nature and rarely resolve spontaneously [5]. Endovascular repair with either transarterial or transvenous coil embolization is required and the success rates vary between 55 and 99\% [6-8]. Transvenous approach for embolization of the cavernous sinus involves catheterization of the inferior petrosal sinus followed by the cavernous sinus. The aim is to occlude the fistula and maintain patency of the parent artery. In rare instances, treatment requires direct endovascular access of the superior ophthalmic vein, using an upper eyelid cut-down technique. Few documented cases of spontaneous resolution of type A fistulas are reported in the literature, varying anywhere from a few days to 6 months [9-16]. The exact mechanism of this process is not known. In this case, it is possible that the initial breach in the wall of the carotid artery was very small, considering the difficulty of transarterial catheterization, and spontaneously healed or endothelialized as with healing of an arterial dissection. Another mechanism that has been postulated is the effect of iodinated contrast media on vascular endothelium leading to thrombosis $[14,15]$. In another case report, carotid massage ipsilateral to the fistula resulted in spontaneous closure 2 weeks after the patient's catheter angiogram [17].

\section{Conclusion}

Our case represents a rare occurrence of spontaneous resolution of a direct CCF. Spontaneous healing of an arterial injury or catheter manipulation during initial conventional angiogram may have played a role in the closure of the fistula.

\section{Statement of Ethics}

Subjects have given their informed consent and the study protocol has been approved by the institute's committee on human research. No animal experiments were conducted.

\section{Disclosure Statement}

The authors have no conflicts of interest to disclose. 
Naragum et al.: Spontaneous Resolution of Post-Traumatic Direct Carotid-Cavernous Fistula

\section{References}

1 Brosnahan D, McFadzean RM, Teasdale E: Neuro-ophthalmic features of carotid cavernous fistulas and their treatment by endoarterial balloon embolisation. J Neurol Neurosurg Psychiatry 1992;55:553-556.

2 Halbach VV, Hieshima GB, Higashida RT, Reicher M: Carotid cavernous fistulae: indications for urgent treatment. Am J Roentgenol 1987;149:587-593.

3 Chaudhry IA, Elkhamry SM, Al-Rashed W, Bosley TM: Carotid cavernous fistula: ophthalmological implications. Middle East Afr J Ophthalmol 2009;16:57-63.

4 Barrow DL, Spector RH, Braun IF, Landman JA, Tindall SC, Tindall GT: Classification and treatment of spontaneous carotid-cavernous sinus fistulas. J Neurosurg 1985;62:248-256.

5 Korkmazer B, Kocak B, Tureci E, Islak C, Kocer N, Kizilkilic O: Endovascular treatment of carotid cavernous sinus fistula: a systematic review. World J Radiol 2013;5:143-155.

6 Lasjaunias P, Berenstein A: Surgical Neuroangiography: 2 Endovascular Treatment of Craniofacial Lesions. Springer Science and Business Media, 2012.

7 Tjoumakaris SI, Jabbour PM, Rosenwasser RH: Neuroendovascular management of carotid cavernous fistulae. Neurosurg Clin N Am 2009;20:447-452.

8 Debrun GM: Endovascular management of carotid cavernous fistulas; in Valavanis A (ed): Interventional Neuroradiology. Medical Radiology (Diagnostic Imaging and Radiation Oncology). Springer, Berlin Heidelberg, pp 23-34.

9 Graves VB, Strother CM, Weinstein JM, Letellier M: Giant intracavernous carotid aneurysm after spontaneous thrombosis of a carotid cavernous sinus fistula. Am J Neuroradiol 1988;9:595-597.

10 Churojana A, Chawalaparit O, Chiewwit P, Suthipongchai S: Spontaneous occlusion of a bilateral post traumatic carotid cavernous fistula. Interv Neuroradiol 2001;7:245-252.

11 Meena US, Gupta P, Shrivastava T, Purohit D: Spontaneous closure of posttraumatic high-flow carotidcavernous fistula following cerebral angiography. Asian J Neurosurg 2016;11:172.

12 Luo CB, Teng MM, Chang FC, Chang CY: Spontaneous thrombosis and complete disappearance of traumatic carotid-cavernous fistulas after angiography. J Chin Med Assoc 2005;68:487-490.

13 Voigt K, Sauer M, Dichgans J: Spontaneous occlusion of a bilateral caroticocavernous fistula studied by serial angiography. Neuroradiology 1971;2:207-211.

14 Nishijima M, Iwai R, Horie Y, Oka N, Takaku A: Spontaneous occlusion of traumatic carotid cavernous fistula after orbital venography. Surg Neurol 1985;23:489-492.

15 Castillo M, Silverstein M, Hoffman JC, Barrow D: Spontaneous thrombosis of a direct carotid cavernous sinus fistula: confirmation by Gd-DTPA-enhanced MR. Am J Neuroradiol 1989;10(suppl 5):S75-S76.

16 Alkhani A, Willinsky R, TerBrugge K: Spontaneous resolution of bilateral traumatic carotid cavernous fistulas and development of trans-sellar intercarotid vascular communication: case report. Surg Neurol 1999;52:627629.

17 Sobani ZA, Ali A: Spontaneous resolution of a trauma induced direct carotid cavernous fistula. Int J Case Rep Imag 2012;2:18-20. 